\title{
Ankle arthroscopy: the wave that's coming
}

\author{
J. Vega ${ }^{1,2,3} \cdot$ J. Karlsson ${ }^{4}$ - G. M. M. J. Kerkhoffs ${ }^{5,6,7} \cdot$ M. Dalmau-Pastor $^{1,2}(1)$
}

Received: 13 November 2019 / Accepted: 19 November 2019 / Published online: 29 November 2019

(c) European Society of Sports Traumatology, Knee Surgery, Arthroscopy (ESSKA) 2019

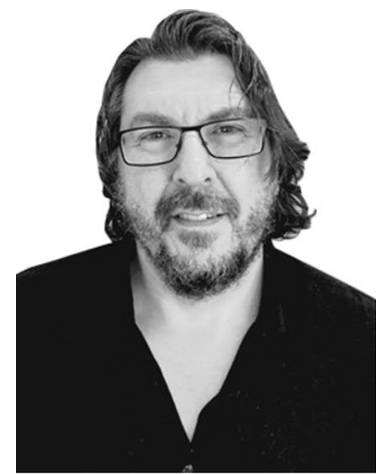

Jordi Vega

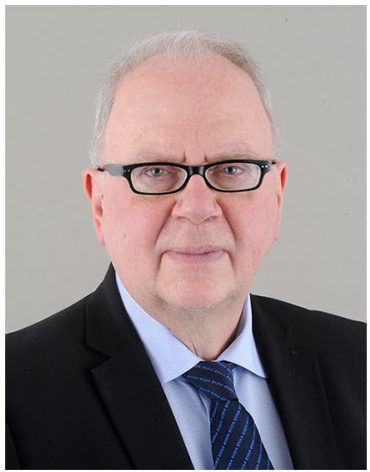

Jon Karlsson

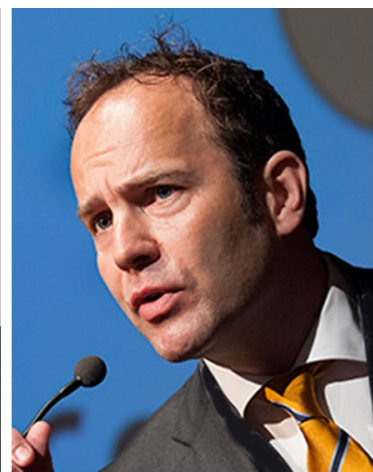

Gino MMJ Kerkhoffs

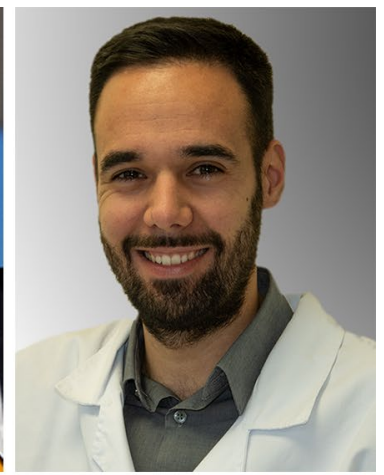

Miki Dalmau-Pastor
Increased interest in ankle pathology and arthroscopic procedures has been observed in the last few years and this KSSTA special issue is a good example of this [2-8, 10, 14-22, 24-30].

M. Dalmau-Pastor

mikeldalmau@ub.edu

1 Human Anatomy Unit, Department of Pathology and Experimental Therapeutics, School of Medicine, University of Barcelona, C/ Feixa Llarga, s/n, Hospitalet de Llobregat, 09806 Barcelona, Spain

2 GRECMIP-MIFAS (Groupe de Recherche et d'Etude en Chirurgie Mini-Invasive du Pied-Minimally Invasive Foot and Ankle Society), Merignac, France

3 Foot and Ankle Unit, iMove Tres Torres, Barcelona, Spain

4 Department of Orthopaedics, Sahlgrenska University Hospital, Sahlgrenska Academy, Gothenburg University, Gothenburg, Sweden

5 Chair Department of Orthopedic Surgery, Academic Medical Center, University of Amsterdam, Meibergdreef 9, 1105 AZ Amsterdam, The Netherlands

6 Chair Academic Center for Evidence Based Sports Medicine (ACES), Meibergdreef 9, 1105 AZ Amsterdam, The Netherlands

7 Co-Chair Amsterdam Collaboration for Health and Safety in Sports (ACHSS), AMC/VUmc IOC Research Center, Amsterdam, The Netherlands
In 2016, the KSSTA presented a special issue on ankle joint disorders following lateral ankle sprains. At that time, the editors wrote: "With the growing knowledge on ankle joint disorders, it appears that this injury (referring to the lateral ankle sprain) causes more damage to the ankle joint than was previously assumed" and they claimed that "There is no simple lateral ankle sprain" [12].

Ankle sprain is a common problem [31]; most individuals may suffer one or more in their lives and chronic ankle complaints can be the result in nearly half of them. An inversion ankle sprain, the most common ankle trauma, involves a lateral ligament injury that apparently does not always heal properly, resulting in chronic pain in approximately 30-40\% of patients [9], numbers which are most probably underestimated. The new evidence presented in this special issue states that the most probable reason for this is the intra-articular location of the superior fascicle of the anterior talofibular ligament, which is the first part of the ligament to be injured in an inversion ankle sprain [5, 25]. Its intra-articular disposition could explain its impaired ability for healing and injury to this small fascicle will not cause traditional ankle instability but rather a low degree of instability or microinstability. On the other hand, an injury affecting the rest of the lateral ligaments would cause lateral ankle instability. As has been observed at the Barcelona School of Orthopedic Surgical Anatomy, the ATFL's inferior fascicle and the CFL 
are connected by arciform fibres and they form the lateral fibulotalocalcaneal ligament (LFTCL) complex [25]. The LFTCL complex is an extra-articular ligament complex and thus retains healing capacity. It is an isometric structure and is regarded as the main lateral ankle joint stabiliser [25].

As studies report, secondary intra-articular ankle injuries are a common finding in patients with ankle instability $[1$, $11,13,23]$, either classical ankle instability or microinstability. Ankle microinstability is regarded as a subtle form of mechanical ankle instability resulting from an injury that affects the ATFL's superior fascicle, while classical ankle instability involves an injury to the LFTCL complex. However, no studies have been conducted to ascertain whether the inverse relationship exists: is ankle instability or microinstability present in those ankles that have some kind of intra-articular pathology? Could it be that the partial injury of the ATFL's superior fascicle remains hidden during the treatment of some or most intra-articular ankle pathology?

We do not have the answer to these questions, but it makes sense that one of the joints where more sprains occur is also the joint where more intra-articular lesions will be found as a direct consequence of these sprains and the resulting instability. In particular, when one of the injured ligaments does not heal properly with conservative treatment... "There is no simple lateral ankle sprain" [12].

The classical open treatment of ankle instability never treats concomitant pathology associated with ankle instability and only focuses on ligament repair or reconstruction. The arthroscopic treatment of ankle instability has the advantage that concomitant intra-articular pathology can be treated simultaneously. As observed in this special issue, arthroscopy has become a real option for treating ankle instability and associated problems. Future evidence will answer the question of whether or not arthroscopy will become the gold standard for the treatment of ankle instability in the future.

The arthroscopic technique has evolved in every joint from diagnostic arthroscopy (first generation) to debridement/resection arthroscopy (second generation) and finally to arthroscopic tissue repair (third generation). This natural evolution is leading to new arthroscopic surgical techniques to repair or reconstruct ankle ligaments. Together with the new concept of ankle microinstability and the advances in the knowledge of the anatomy of the ankle ligaments, this has increased interest in the ankle joint.

Only through a detailed knowledge of ankle anatomy, especially arthroscopic anatomy, and step-by-step learning, can surgeons acquire the ability to reproduce the new arthroscopic techniques for the ankle and, through them, treat patients more effectively. As a consequence, the number of ankle arthroscopic procedures has increased in the last few years worldwide and it will increase even further in the next years as surgeons treat not only major ankle instability but minor or microinstability as well, preventing secondary intra-articular lesions.

A big wave is coming. Be prepared.

\section{Compliance with ethical standards}

Conflict of interest The authors declare that they have no conflicts of interest.

\section{References}

1. Choi WJ, Lee JW, Han SH, Kim BS, Lee SK (2008) Chronic lateral ankle instability: the effect of intra-articular lesions on clinical outcome. Am J Sports Med 36(11):2167-2172

2. Cordier G, Lebecque J, Vega J, Dalmau-Pastor M (2019) Arthroscopic ankle lateral ligament repair with biological augmentation gives excellent results in case of chronic ankle instability. Knee Surg Sports Traumatol Arthrosc. https://doi.org/10.1007/s0016 7-019-05650-9

3. Cordier G, Dalmau-Pastor M, Michels F (2019) Endoscopic anatomic ligament reconstruction is a reliable option to treat arthroscopically chronic ankle instability: outcome at 2 year follow-up. Knee Surg Sports Traumatol Arthrosc. https://doi.org/10.1007/ s00167-019-05793-9

4. Dalmau-Pastor M, Malagelada F, Kerkhoffs GMMJ, Karlsson J, Manzanares MC, Vega J (2018) The anterior tibiofibular ligament has a constant distal fascicle that contacts the anterolateral part of the talus. Knee Surg Sports Traumatol Arthrosc. https://doi. org/10.1007/s00167-018-5123-z

5. Dalmau-Pastor M, Malagelada F, Kerkhoffs GM, Karlsson J, Guelfi M, Vega J (2019) Redefining anterior ankle arthroscopic anatomy: medial and lateral ankle collateral ligaments are visible through dorsiflexion and non-distraction anterior ankle arthroscopy. Knee Surg Sports Traumatol Arthrosc. https://doi. org/10.1007/s00167-019-05603-2

6. Dalmau-Pastor M, Malagelada F, Calder J, Manzanares MC, Vega J (2019) The lateral ankle ligaments are interconnected: the medial connecting fibres between the anterior talofibular, calcaneofibular and posterior talofibular ligaments. Knee Surg Sports Traumatol Arthrosc. https://doi.org/10.1007/s00167-019-05794-8

7. Deng E, Shi W, Jiao C, Xie X, Jiang D, Chen L, Hu Y, Guo Q (2019) Reattachment of the superior peroneal retinaculum versus the bone block procedure for the treatment of recurrent peroneal tendon dislocation: two safe and effective techniques. Knee Surg Sports Traumatol Arthrosc 27(9):2877-2883

8. D'Hooghe P, Pereira H, Kelley J, Anderson N, Fuld R, Kumparatana P, Baldini T, Hunt KJ (2019) The CFL fails before the ATFL immediately after combined ligament repair in a biomechanical cadaveric model. Knee Surg Sports Traumatol Arthrosc. https:// doi.org/10.1007/s00167-019-05626-9

9. Gerber JP, Williams GN, Scoville CR, Arciero RA, Taylor DC (1998) Persistent disability associated with ankle sprains: a prospective examination of an athletic population. Foot Ankle Int 19(10):653-660

10. Guelfi M, Vega J, Malagelada F, Dalmau-Pastor M (2019) The arthroscopic all-inside ankle lateral collateral ligament repair is a safe and reproducible technique. Knee Surg Sports Traumatol Arthrosc. https://doi.org/10.1007/s00167-019-05427-0 
11. Hintermann B, Boss A, Schäfer D (2002) Arthroscopic findings in patients with chronic ankle instability. Am J Sports Med 30(3):402-409

12. Kerkhoffs GM, Kennedy JG, Calder JD, Karlsson J (2016) There is no simple lateral ankle sprain. Knee Surg Sports Traumatol Arthrosc 24(4):941-943

13. Komenda GA, Ferkel RD (1999) Arthroscopic findings associated with the unstable ankle. Foot Ankle Int 20(11):708-713

14. Lambers KTA, Dahmen J, Reilingh ML, van Bergen CJA, Stufkens SAS, Kerkhoffs GMMJ (2019) Arthroscopic lift, drill, fill and fix (LDFF) is an effective treatment option for primary talar osteochondral defects. Knee Surg Sports Traumatol Arthrosc. https://doi.org/10.1007/s00167-019-05687-w

15. Lee JH, Lee SH, Jung HW, Jang WY (2019) Modified Broström procedure in patients with chronic ankle instability is superior to conservative treatment in terms of muscle endurance and postural stability. Knee Surg Sports Traumatol Arthrosc. https://doi. org/10.1007/s00167-019-05582-4

16. Li Q, Tu Y, Chen J, Shan J, Yung PS, Ling SK, Hua Y (2019) Reverse anterolateral drawer test is more sensitive and accurate for diagnosing chronic anterior talofibular ligament injury. Knee Surg Sports Traumatol Arthrosc. https://doi.org/10.1007/s0016 7-019-05705-x

17. Lopa S, Colombini A, Moretti M, de Girolamo L (2019) Injective mesenchymal stem cell-based treatments for knee osteoarthritis: from mechanisms of actionn to current clinical evidences. Knee Surg Sports Traumatol Arthrosc 27(6):2003-2020

18. Malagelada F, Vega J, Guelfi M, Kerkhoffs G, Karlsson J, Dalmau-Pastor M (2019) Anatomic lectures on structures at risk prior to cadaveric courses reduce injury to the superficial peroneal nerve, the commonest complication in ankle arthroscopy. Knee Surg Sports Traumatol Arthrosc. https://doi.org/10.1007/s0016 7-019-05373-x

19. Malagelada F, Stephen J, Dalmau-Pastor M, Masci L, Yeh M, Vega J, Calder J (2019) Pressure changes in the Kager fat pad at the extremes of ankle motion suggest a potential role in Achilles tendinopathy. Knee Surg Sports Traumatol Arthrosc. https://doi. org/10.1007/s00167-019-05585-1

20. Michels F, Matricali G, Guillo S, Vanrietvelde F, Pottel H, Stockmans F (2019) An oblique fibular tunnel is recommended when reconstructing the ATFL and CFL. Knee Surg Sports Traumatol Arthrosc. https://doi.org/10.1007/s00167-019-05583-3

21. Pereira BS, van Dijk CN, Andrade R, Casaroli-Marano RP, Espregueira-Mendes J, Oliva XM (2019) The calcaneofibular ligament has distinct anatomic morphological variants: an anatomical cadaveric study. Knee Surg Sports Traumatol Arthrosc. https:// doi.org/10.1007/s00167-019-05797-5
22. Schon JM, Brady AW, Krob JJ, Lockard CA, Marchetti DC, Dornan GJ, Clanton TO (2019) Defining the three most responsive and specific CT measurements of ankle syndesmotic malreduction. Knee Surg Sports Traumatol Arthrosc 27(9):2863-2876

23. Taga I, Shino K, Inoue M, Nakata K, Maeda A (1993) Articular cartilage lesions in ankles with lateral ligament injury. An arthroscopic study. Am J Sports Med 21(1):120-126

24. Vega J, Allmendinger J, Malagelada F, Guelfi M, Dalmau-Pastor M (2017) Combined arthroscopic all-inside repair of lateral and medial ankle ligaments is an effective treatment for rotational ankle instability. Knee Surg Sports Traumatol Arthrosc. https:// doi.org/10.1007/s00167-017-4736-y

25. Vega J, Malagelada F, Manzanares Céspedes MC, Dalmau-Pastor M (2018) The lateral fibulotalocalcaneal ligament complex: an ankle stabilizing isometric structure. Knee Surg Sports Traumatol Arthrosc. https://doi.org/10.1007/s00167-018-5188-8

26. Vega J, Montesinos E, Malagelada F, Baduell A, Guelfi M, Dalmau-Pastor M (2018) Arthroscopic all-inside anterior talo-fibular ligament repair with suture augmentation gives excellent results in case of poor ligament tissue remnant quality. Knee Surg Sports Traumatol Arthrosc. https://doi.org/10.1007/s00167-018-5117-x

27. Vega J, Poggio D, Heyrani N, Malagelada F, Guelfi M, Sarcon A, Dalmau-Pastor M (2019) Arthroscopic all-inside ATiFL's distal fascicle transfer for ATFL's superior fascicle reconstruction or biological augmentation of lateral ligament repair. Knee Surg Sports Traumatol Arthrosc. https://doi.org/10.1007/s00167-01905460-z

28. Vega J, Malagelada F, Dalmau-Pastor M (2019) Arthroscopic allinside ATFL and CFL repair is feasible and provides excellent results in patients with chronic ankle instability. Knee Surg Sports Traumatol Arthrosc. https://doi.org/10.1007/s00167-019-05676-z

29. Vega J, Malagelada F, Karlsson J, Kerkhoffs GMMJ, Guelfi M, Dalmau-Pastor M (2019) A step-by-step arthroscopic examination of the anterior ankle compartment. Knee Surg Sports Traumatol Arthrosc. https://doi.org/10.1007/s00167-019-05756-0

30. Ventura A, Legnani C, Corradini C, Borgo E (2018) Lateral ligament reconstruction and augmented direct anatomical repair restore ligament laxity in patients suffering from chronic ankle instability up to 15 years from surgery. Knee Surg Sports Traumatol Arthrosc. https://doi.org/10.1007/s00167-018-5244-4

31. Waterman BR, Owens BD, Davey S, Zacchilli MA, Belmont PJ (2010) The epidemiology of ankle sprains in the United States. J Bone Joint Surg Am 92(13):2279-2284

Publisher's Note Springer Nature remains neutral with regard to jurisdictional claims in published maps and institutional affiliations. 